\title{
ANTROPOLOGIA DEL TURISMO EN EL SIGLO XXI
}

\author{
Maximiliano E. KORSTANJE \\ Universidad de Palermo (Argentina) \\ maxikorstanje@arnet.com.ar
}

\section{ANTHROPOLOGY OF TOURISM FOR XXIth century ${ }^{1}$}

Desde la introducción, por parte de Jafar Jafari (2005), de las cuatro plataformas del turismo; recuérdese, apologética la cual remarca los beneficios del turismo en las comunidades locales, como la precautoria en cuyo caso se reparan en los efectos no deseados, pasando por la adaptativa y la científica, no ha existido un esfuerzo comprensivo (sostenido en el tiempo) por parte de los investigadores por revisar los sustentos epistemológicos de la disciplina. El turismo hoy en día se lo define como una actividad netamente económicaproductiva y en razón de tal, el marketing y el management han extendido sus tentáculos influyendo notablemente no solo en los programas de estudios, sino también en lo que se produce académicamente. Según este paradigma netamente instrumentalista, el turismo sigue patrones de producción y consumos específicos nacidos del ethos capitalista (Korstanje, 2006). Más interesados por proteger el producto turístico de las anomalías del sistema que por comprender la causalidad del fenómeno, gran parte de los investigadores aplican encuestas de mercadeo a turistas en los principales centros de consumo del mundo, aduciendo criterios de objetividad. En el fondo, se trata solo de un abordaje exploratorio y superficial que focaliza en las expectativas de la demanda. Esta tendencia, que se legitima así misma en forma endógama; es decir rechazando la posición critica, ha adoptado ciertos elementos con-

\footnotetext{
1 Desde la dirección de la Revista de Antropología Experimental hace un año invitamos a editar este monográfico al profesor Maximiliano Korstanje (Universidad de Palermo, Argentina, International Society for Philosophers, UK, Tourism Crisis Management Institute. University of Florida, US) y al que agradecemos el trabajo realizado. Sabíamos la enorme calidad y pertinencia del trabajo que él realiza (es un colaborador asiduo nuestro, muy apreciado y siempre celebrado por los lectores), partiamos de la idea de que los contenidos de nuestra publicación estuvieran en el epicentro de las temáticas actuales sin renunciar ni a la independencia ni a la experimentalidad- El resultdo no ha podido ser más satisfactorio.
} 
ceptuales de las ciencias sociales (como por ejemplo las normas de la sociología, el patrimonio de la antropología) pero los ha amalgamado en un "pastiche", el cual cuando no llega a resultados contradictorios o descriptivos, duerme en la voluntad de lo que el turista desea (Korstanje, 2010a; 2012; Thirkettle \& Korstanje, 2013). Empero como bien ha acertado Malinowski (1981), existen ciertos problemas cuando preguntamos que se deriva de dos axiomas significativos. El primero de ellos, es que el entrevistado puede simplemente estar mintiendo, el segundo y más profundo es que éste no tiene idea de las razones que lo llevan a comportarse de tal o cual forma. El mismo Malinowski en su modelo teórico sobre las funciones sociales había establecido un importante rol para el descanso y el esparcimiento.

Este gran sesgo culminó con la idea de que el turismo sólo podía ser una actividad moderna nacida de la extrema racionalidad y abstracción del sistema capitalista occidental. Se desdibujaron así miles de años de historia sobre civilizaciones como los sumerios, hititas. Incas, aztecas y romanos que habían desarrollado canales de comercio y de movilidad similares el turismo moderno. Ello se debió a la miopía de los primeros historiadores del turismo que tomaron la realidad de la edad media, caracterizada por su baja movilidad, como una constante en otras épocas de la historia. De esta forma se antepuso el pensamiento de que el turismo fue una creación racional europea exclusivamente (Korstanje, 2009; 2010b). Particularmente, la investigación turística comenzó a operar con ciertas doctrinas de las Ciencias Sociales pero articuladas para no destruir su razón instrumentalista. De esa forma, la antropología del turismo fue consolidándose por el préstamo de ciertos saberes ya establecidos, mientras otros fueron silenciados. A la vez que miles de trabajos enfatizan sobre el patrimonio turístico (por la rentabilidad que este genera a los grandes inversores), sólo algunos especialistas en soledad estudian la influencia de los mitos antiguos para recrear antiguas formas de turismo, o el rol que juega la hospitalidad como centro simbólico de solidaridad (Korstanje, 2011).

En este contexto, el presente número especial, dedicado completamente a la antropología del turismo intenta desenterrar viejos paradigmas ya conocidos para los etnólogos y llevarlo al campo de los estudios turísticos. La antropología, como disciplina, tiene aún mucho para decir lejos de los estudios econométricos. El turismo, siguiendo a JiménezGuzmán (1986) es un "hecho turístico". Antes que nada mi eterno agradecimiento a todos los participantes y al Dr. José Luís Anta-Felez por abrirme las puertas de esta prestigiosa Revista de Antropología Experimental. La versatilidad, erudición, diferencia de concepción de todos los trabajos hace de este número algo especial.

En una primera instancia, Korstanje nos trae un primer trabajo que hace referencia a la ruptura epistémica del turista cuando debe abandonar su hogar, y en base a ello, como se configuran sus miedos y expectativas. La hospitalidad como institución social serviría como reguladora entre los temores de huéspedes y anfitriones. Agradecemos en segundo lugar, la participación del economista Francisco Muñoz de Escalona quien hace una profunda crítica de los paradigmas vigentes en la epistemología del turismo. Su posición sostiene que es necesario repensar el rol mercantilista del turismo y del desarrollo para establecer formas negociadas de comprensión. A diferencia de Korstanje, Muñoz de Escalona entiende que el turismo no es ni una institución social milenaria, como tampoco una actividad puramente consumista.

M. Mendoza Ontiveros, M. A Pacheco, G Rodríguez-Muñoz, y M J Fernández-Aldecua concentran sus esfuerzos en la representación de género en los establecimientos turísticos de zona de Huatulco, México. Los especialistas explican que el turismo no solo modifica la forma en la cual la mujer se concibe, sino que además altera los imaginarios colectivos que le dan sentido a ese ser-mujer. Por su parte, Agustín Santana Talavera examina la influencia de la imagen visual en la construcción del turismo, las variables que componen el fenómeno como así los procesos de sentido resultantes. En tanto fenómeno social, la valoración del producto turístico apela a un sentido de pertenencia que es recreado y vendido por los 
intermediarios globales. Los antropólogos españoles, Antonio Martín-Cabello y Almudena García-Manso estudian el rol del mochilero dentro de los canales de comercialización alternativos al turismo clásico. Empleando la etnografía como método distintivo, en este trabajo, se resume que existen diferencias entre la subcultura de los mochileros y de los expatriados corporativos. El sexto trabajo, nuevamente a cargo de M. Korstanje sintetiza los resultados de una investigación llevada a cabo sobre los divorcios post vacacionales. Para muchas personas, el viaje turístico o de placer representa un estado de tensión en donde las crisis matrimoniales se acrecientan. Como resultado del síndrome de estrés post-vacacional, algunas parejas deciden entablar el divorcio luego de un soñado viaje recreativo. Lo que subyace es el contraste entre "el sentido sagrado del paraíso imaginado" que emula las vacaciones, y la rutina de trabajo postmoderno.

Nuevamente, Francisco Muñoz de Escalona presenta un debate espitemológico sobre las posibilidades del turismo de evitar una inminente fragmentación de saberes. Para el estudioso español, la diversificación de unidades de análisis tiene más que ver con la necesidad de establecer criterios comerciales que sustenten doctorados y programas de investigación que con la consolidación de una ciencia. Si el turismo es en sí una misma unidad, parte de esta tendencia comercial se evidencia en la necesidad de partir al turismo en segmentos, tales como sociología del turismo, filosofía del turismo, geografía del turismo etc.

Tenemos el placer de contar también con la colaboración de Norma Fuller de la Pontificia Universidad Católica de Perú, quien tiene ya por estos años una larga trayectoria en la antropología del turismo. En su trabajo, ella retoma las contribuciones y las polémicas de Dean Maccannell respecto del papel que juega la autenticidad en el turismo. En tanto escenificación, el turismo recrea situaciones idílicas con el fin de fijar formas estereotipadas de experiencia. No obstante, el turismo parece algo más complejo que un simple productor de escenografías como sostiene el antropólogo americano. La escena ofrece un espectáculo pero eso se debe a la voluntad de los agentes locales a ser parte de ese proceso, es decir, en la re-elaboración preactiva de sus propios intereses. La discusión debe darse sobre la función social del valor para reciclar culturas que en el poder alienador del turismo como pretendía Dean Maccannell. Las disputas y los conflictos locales examinados por Fuller en Perú dan cuenta de las inconsistencias actuales en la teoría de la autenticidad.

En su artículo "memorias de un arquitecto, Isusko Vivas Ziarrusta \& Amaia Lekerikabeaskoa Gaztañaga retratan la obra del arquitecto Aldo Rossi en un programa cultural que reconsidera nuevamente nuestro habitar en el mundo. La necesidad de comprender el espacio desde la teoría de la post-modernidad lleva a cuestionarnos las formas en que el cuerpo, la ciudad y la arquitectura dialogan.

Por último pero no por ello menos importante, dos grandes investigadores de renombre mundial fueron invitados a participaron pequeñas intervenciones. Geoffrey Skoll profesor Emérito de la Universidad de Nueva York en Buffalo, USA y Babu George, investigador del Swiss Management Centre en Suiza. El primero llama la atención del turismo como "la doncella" del imperialismo. Según su postura, los movimientos turísticos acompañan a los crecimientos económicos e intercambio de bienes modificando las fronteras establecidas. Para el segundo, el turismo se ha consolidado gracias a una tergiversación conceptual de lo que se denomina la autenticidad. La idea que sitúa a la experiencia dentro del binomio auténtico vs. falso es no solo una quimera, sino una disposición ideológica de control que tiene lugar en el mundo capitalista. Estas preocupaciones han llevado a Rodanthi Tzanelli de la Universidad de Leeds a reflexionar sobre la nueva ética postmoderna que no solo cosifica al otro excluido con el fin de asignarle un valor para su explotación, sino que introduce la tecnología como mediadora entre la racionalidad occidental y la pobreza que ella ha generado en la periferia. El turismo, en este proceso, ha servido como una industria donde se muestra al otro aquello que dentro se reprime. El turismo en las favelas es usado como un mecanismo disciplinario que normaliza la pobreza. 


\section{Referencias}

Jafari, J. (2005). "El turismo como disciplina científica". Política y sociedad, 42(1), 39-56.

Jiménez-Guzmán, L. F. (1986). Teoría Turística: un enfoque integral del hecho social. Bogotá, Universidad Externado de Colombia.

Korstanje, M. E (2006) "El Viaje, una crítica al concepto de no lugares". Atenea Digital Vol. 10: 221-238

Korstanje, M. E. (2009). "Reconsidering the roots of event management: leisure in ancient Rome". Event Management, 13(3), 197-203.

Korstanje, M. E. (2010a). "Discurso De La Perspectiva Técnica En El Estudio Del Turismo". Turismo y Desarrollo Local, (7): 1-15.

Korstanje, M. E. (2010b). "The aristocratic leisure of the Caesars: a comparative study between Roman leisure and modern tourism". Caderno Virtual de Turismo,10(2), 102-120.

Korstanje, M. E. (2011). "Mitologia y turismo: La exégesis como interpretación hermenéutica". Estudios y perspectivas en turismo, 20(6), 1258-1280.

Korstanje, M. (2012). "Reconsidering cultural tourism: an anthropologist's perspective". Journal of Heritage Tourism, 7(2), 179-184.

Malinowski, B. (1981). Una teoría científica de la cultura. Barcelona, Edhasa.

Thirkettle, A., \& Korstanje, M. E. (2013). Creating a new epistemiology for tourism and hospitality disciplines. International Journal of Qualitative Research in Services, 1(1), 13-34.

\section{0}

